\title{
Mantle electrical conductivity profile of Niger delta region
}

\author{
Daniel N Obiora ${ }^{1, *}$, Francisca N Okeke $^{1}, \mathrm{~K}_{\text {Yumoto }}^{2}$ and Stan O Agha ${ }^{3}$ \\ ${ }^{1}$ Department of Physics and Astronomy, University of Nigeria, Nsukka 410, Nigeria. \\ ${ }^{2}$ Space Environment Research Centre, Kyushu University, Fukuoka 812-8581, Japan. \\ ${ }^{3}$ Department of Industrial Physics, Ebonyi State University, PMB 053, Abakaliki, Nigeria. \\ *Corresponding author.e-mail: daniel.obiora@unn.edu.ng
}

The mantle electrical conductivity-depth profile of the Niger delta region in Nigeria has been determined using solar quiet day ionospheric current (Sq). The magnetometer data obtained in 2010 from geomagnetic stations installed in Lagos by magnetic dataset (MAGDAS) in 2008 and data from magnetometers installed in some parts of Niger delta by Center for Basic Space Science, University of Nigeria, Nsukka, were employed in this study. Gauss spherical harmonic analysis (SHA) method was used to separate the internal and external field contributions to Sq current system. The result depicted that the conductivity profile rose steadily from about $0.032 \mathrm{~S} / \mathrm{m}$ at a depth of $89 \mathrm{~km}$ to $0.041 \mathrm{~S} / \mathrm{m}$ at $100 \mathrm{~km}$ and $0.09 \mathrm{~S} / \mathrm{m}$ at $221 \mathrm{~km}$. This high conductivity region agreed with the global seismic low velocity region, the asthenosphere. The conductivity profile continued increasing downward until it got to $0.157 \mathrm{~S} / \mathrm{m}$ at a depth of about $373 \mathrm{~km}$ (close to the base of upper mantle), $0.201 \mathrm{~S} / \mathrm{m}$ at $784 \mathrm{~km}$ and reached $0.243 \mathrm{~S} / \mathrm{m}$ at a depth of $1179 \mathrm{~km}$ at the lower mantle.

\section{Introduction}

Electrical conductivity is the property of a material which describes the relative ease with which the material can allow the flow of current through it. The current which flows in deeper regions of the Earth such as the upper mantle has been noted to be induced from the geomagnetic field of external origin. Specifically, the quiet-day ionospheric current flowing in the Earth's upper atmosphere produces a varying magnetic field having a 24 -h period described as Sq field. Both the Sq field (external source) and the field from the current induced in the Earth (internal source) can be measured by magnetometers in magnetic observatories.

The magnitude, direction and depth of penetration of the induced currents are determined by the characteristics of the source current as well as the distribution of electrically conducting materials on the Earth. At the Earth's surface, the measured field is a mixture of both external (source) and internal (induced) components from the current. Using spherical harmonic analysis (SHA), these currents are separated into their external and internal components and this separation is used to determine the electrical conductivity of the Earth.

This method of probing the conductivity of the Earth started with the work of Chapman and Bartels (1940) who made the first significant Earth conductivity determinations with the separated external and internal fields. Schmucker (1970) devised a method of profiling the Earth's conductivity with a transfer function that uses the external and internal spherical harmonic coefficients at a given site. This function allowed the determination of a depth to equivalent substitute

Keywords. Conductivity profile; Niger delta; solar quiet day current; spherical harmonic analysis (SHA); mantle; magnetic data. 
conductors that would produce the observed fields at the Earth's surface. Campbell and Anderssen (1983) and Campbell (1989) expanded the technique for application to the continental Sq system. Okeke (2000) from her work noted that a new model of the Sq current system could be used to obtain a mantle electrical conductivity profile for hemispheres.

This Sq method of probing the electrical conductivity of the Earth has been applied in other regions of the world (Campbell and Schiffmacher 1988; Arora et al. 1995; Campbell et al. 1998; Agha and Okeke 2007; Obiekezie and Okeke 2010) but none of these works had been carried out in Nigeria. Obiekezie and Okeke (2010) worked on conductivity-depth profile of upper mantle in the West African subregions but Nigeria was not part of the subregions they covered.

Obiora and Okeke (2011) applied solar quiet daily $(\mathrm{Sq})$ ionospheric current variations in their preliminary study of application of Sq current in determining the depth to subsurface structure in Niger delta and found that Sq current could be used to probe the solid Earth up to a depth of $560 \mathrm{~km}$.

The purpose of this study is to determine the mantle electrical conductivity-depth profile of Niger delta region using the solar quiet day ionospheric current.

\section{Source of data}

In 2008, the magnetic dataset (MAGDAS), Japan set up a geomagnetic observatory centre at the University of Lagos, Lagos (latitude: $6.813^{\circ}$ and longitude: $3.460^{\circ}$ ). The hourly averaged geomagnetic data obtained from this station and from magnetometers installed in some parts of Niger delta (Benin $6.318^{\circ} \mathrm{N}, 5.615^{\circ} \mathrm{E}$; Asaba $6.183^{\circ} \mathrm{N}, 6.750^{\circ} \mathrm{E}$; Owerri $5.483^{\circ} \mathrm{N}, 7.03^{\circ} \mathrm{E}$ and $\mathrm{Uyo} 5.050^{\circ} \mathrm{N}, 7.933^{\circ} \mathrm{E}$ ) by Center for Basic Space Science, University of Nigeria, Nsukka, in 2010 were employed in this study. Figure 1 shows the Google Earth map of the study area with the geomagnetic stations.

\section{Method of analysis}

The method of analysis involves the differential equations of Maxwell (1873), who showed that all the electromagnetic laws governing electric and magnetic field phenomena could be derived from a few compact mathematical expressions. For the situation in which field measurements are available about a spherical surface that separates the source from the induced currents (and current does not flow across this surface), Maxwell's equations were given a separable series solution in the spherical coordinates $r, \theta$, and $\phi$ by Gauss (1838) in his spherical harmonic analysis (SHA). A solution for the Earth's main field (devised by Gauss 1838) satisfying these requirements have the converging series of terms (Campbell 1997):

$$
V=a \sum_{n=1}^{\infty}\left[\left(\frac{r}{a}\right)^{n} S_{n}^{e}+\left(\frac{a}{r}\right)^{n+1} S_{n}^{i}\right],
$$

where $a$ is the Earth's radius, $R_{e}$. The series solution means that for each value of $n$, the electromagnetic laws are obeyed as if that term was the only contribution to the field.

It is observed from equation (1) that there are two series. The first is made up of terms in $r^{n}$. As $r$ increases, these terms become larger and larger which means that we must be approaching the current source of an external field in the increasing $r$ direction. For the second series, the $(1 / r)^{n}$ terms become larger and larger as $r$ becomes smaller and smaller, which means we must be approaching the current source of an internal field in the decreasing $r$ direction. For the Sq analysis, such series represent a separation of the Earth's magnetic potential function into the composite external (ionospheric source) and internal (induced) contributions of the geomagnetic field. The process allows the construction of the ionospheric dynamo current system and also the induced field gives information on the conductivity structure of the Earth.

When $V$ is determined from measurements of the field about the Earth, analyses show that mostly all the contribution comes from the internal part of the potential function expansion. The magnetic potential of the Sq field measured from the daily mean values at universal time, $T$ from both the external source current and the internal (induced) current is expressed by:

$$
\begin{aligned}
V_{n}^{m}= & C+a \sum_{n=1}^{\infty} \sum_{m=0}^{n}\left\{\left(a_{n}^{m e}\left(\frac{r}{a}\right)^{n}+a_{n}^{m i}\left(\frac{a}{r}\right)^{n+1}\right) \cos (m \phi)\right. \\
& +\left(b_{n}^{m e}\left(\frac{r}{a}\right)^{n}+b_{n}^{m i}\left(\frac{a}{r}\right)^{n+1}\right) \\
& \times \sin (m \phi)\} P_{n}^{m}(\theta)
\end{aligned}
$$

where $C, \theta, a, r$, and $\phi$ denote a constant of integration, the geomagnetic colatitude, the geocentric distance, the Earth's radius and local time of the observatory, respectively. The $a_{n}^{m e}$ and $a_{n}^{m i}$, $b_{n}^{m e}$ and $b_{n}^{m i}$ are Legendre polynomial coefficients, where $e$ and $i$ represent the external and internal values, respectively. $P_{n}^{m}$ are Legendre polynomial functions of colatitude $\theta$ only. They are quasisinusoidal oscillations having $n-m+1$ waves (or 


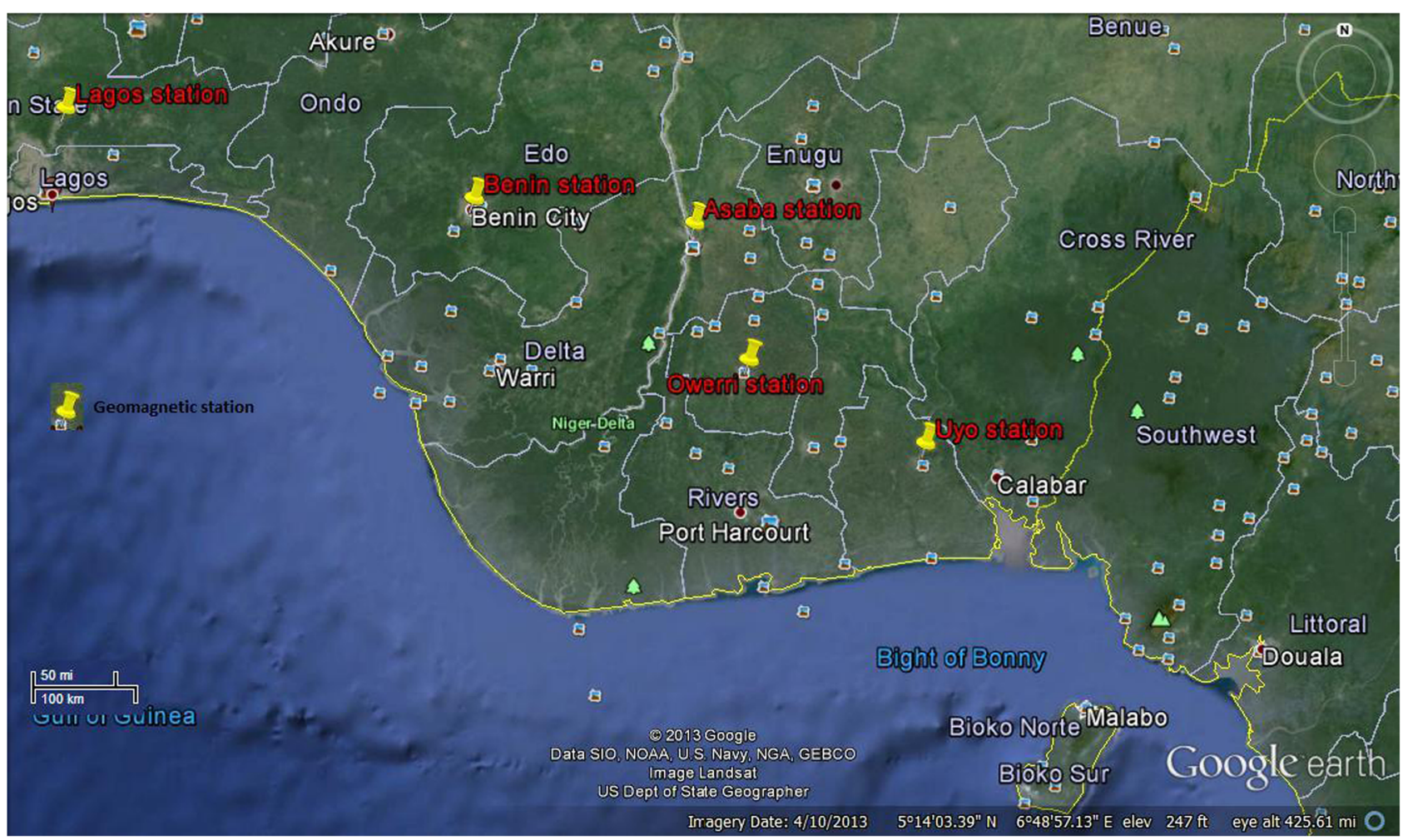

Figure 1. Google Earth map of the study area showing the geomagnetic stations.

just $n$ waves if $m=0$ ) as $\theta$ changes from $0^{\circ}$ to $360^{\circ}$ along a great circle of longitude. Since $\mathrm{Sq}$ is cyclic in $24 \mathrm{~h}$, there are no $m=0$ terms. The integers, $n$ and $m$, are called degree and order respectively, $n$ has a value of 1 or greater and $m$ is always less than or equal to $n$. In Sq analysis, $r \approx a(a=$ the Earth's radius, $R_{e}$ ).

Taking $a_{n}^{m e}+a_{n}^{m i}=A_{n}^{m}$ and $b_{n}^{m e}+b_{n}^{m i}=B_{n}^{m}$, equation (2) could be written as:

$$
\begin{aligned}
V_{n}^{m}(\theta, \phi)= & R_{e} \sum_{n=1}^{\infty} \sum_{m=0}^{n}\left[A_{n}^{m} \cos (m \phi)\right. \\
& \left.+B_{n}^{m} \sin (m \phi)\right] P_{n}^{m}(\theta) .
\end{aligned}
$$

From equation (3), it is observed that the functions multiplying the Legendre terms appear somewhat like a Fourier series: a harmonic series of cosine and sine terms that, when added, will produce the function they are to represent. Two computational restrictions are that $n$ must be greater than or equal to $m$ and that the Legendre series must be truncated at a particular value of $n(=12$, used in this study).

The ionospheric Sq current system for a quiet day is assumed to be fixed in position with respect to the Sun. As the Earth spins $360^{\circ}$ under this fixed system, surface observatories sense the $24 \mathrm{~h}$ change of Sq. Hence, data from a group of observatories distributed in latitude over a narrow sector of the
Earth may be used for spherical analysis. Because the quiet field changes vary slightly from day to day, the $24 \mathrm{~h}$ of time at the observatories can be equated to longitude in the analysis. Thus the 24-, $12-, 8-$, and 6 -h components of the daily field variations correspond to the $(360 / m)^{\circ}$ components of longitudinal field change where the 'order' index $m$ is equal to $1,2,3$, or 4 . The mirror technique using the slice method (Campbell 1997) is applied in analyzing the $\mathrm{Sq}$ variations.

For a geomagnetic component $\mathrm{W}(\mathrm{H}, \mathrm{D}$ or $\mathrm{Z}$, in $\mathrm{nT}$ ), the $\mathrm{Sq}$ fields are reconstructed using (Campbell 1989):

$$
\Delta W=\sum_{m=1}^{4}\left(C_{m} \cos 15 m t+S_{m} \sin 15 m t\right),
$$

where

$C_{m}=A_{m}^{0}+\sum_{Q=1}^{2}\left(A_{m}^{A Q} \cos 30 Q M+B_{m}^{A Q} \sin 30 Q M\right)$

and

$S_{m}=B_{m}^{0}+\sum_{Q=1}^{2}\left(A_{m}^{B Q} \cos 30 Q M+B_{m}^{B Q} \sin 30 Q M\right)$

$m$ is $1, \ldots, 4$ for the $24-, 12-, 8$ - and 6 -h spectral components respectively; $Q$ is 1 for annual and 2 
for semiannual; $M$ is the decimal month (0.0 is January 1 and 12.0 is December 31) and $t$ is the local time in hours. The A's and B's are the Fourier cosine and sine coefficients.

We constructed the Fourier cosine and sine coefficients for each monthly analysis. For each analysis time sample, Sq field Fourier cosine and sine coefficients were represented by values of $X_{c}^{m}, X_{s}^{m}, Y_{c}^{m}, Y_{s}^{m}, Z_{c}^{m}$ and $Z_{s}^{m}$. At each co-latitude, $\theta$, a Fourier analysis along the latitude line provides $m$ sine and cosine coefficients to represent this field for each $X, Y$ and $Z$ component separately. Taking $X_{c}^{m}$ for cosine coefficients and $X_{s}^{m}$ for sine coefficients and in a similar way for the $Y$ and $Z$ field components, the intermediate coefficients; $a_{n}^{m}, b_{n}^{m}, c_{n}^{m}$ and $d_{n}^{m}$ are calculated for $m>0$ using:

$$
\begin{gathered}
a_{n}^{m}=\frac{2 n+1}{4 n(n+1)} \int_{0}^{180}\left[X_{c}^{m} \frac{d P_{n}^{m}}{d \theta} \sin (\theta)+Y_{s}^{m} m P_{n}^{m}\right] d \theta \\
b_{n}^{m}=\frac{2 n+1}{4 n(n+1)} \int_{0}^{180}\left[X_{s}^{m} \frac{d P_{n}^{m}}{d \theta} \sin (\theta)-Y_{c}^{m} m P_{n}^{m}\right] d \theta \\
c_{n}^{m}=\frac{2 n+1}{4} \int_{0}^{180} Z_{c}^{m} P_{n}^{m} \sin (\theta) d \theta \\
d_{n}^{m}=\frac{2 n+1}{4} \int_{0}^{180} Z_{s}^{m} P_{n}^{m} \sin (\theta) d \theta .
\end{gathered}
$$

The integral sign in equation $(4 \mathrm{a}-\mathrm{d})$ means a summation over a $\theta$ range of $0-180^{\circ}$. In the computation of the intermediate values, the integral is replaced by summing over the range in finite increments of $\Delta \theta$ ( $3^{\circ}$ in this study) steps. The size of these steps is selected to be appropriate to the wavelength resolution that is to be accomplished by the SHA fitting. The three components $H, D$ and $Z$ of magnetic variations on the Earth's surface $\left(a=R_{e}\right)$ are expressed as:

$$
\begin{aligned}
H & =\sum_{n} \sum_{m}\left(a_{n}^{m} \cos m \phi+b_{n}^{m} \sin m \phi\right) X_{n}^{m}(\theta) \\
D & =\sum_{n} \sum_{m}\left(-b_{n}^{m} \cos m \phi+a_{n}^{m} \sin m \phi\right) Y_{n}^{m}(\theta) \\
Z & =\sum_{n} \sum_{m}\left(C_{n}^{m} \cos m \phi+d_{n}^{m} \sin m \phi\right) P_{n}^{m}(\theta)
\end{aligned}
$$

where

and

$$
X_{n}^{m}(\theta)=\frac{1}{n} \frac{\partial P_{n}^{m}(\theta)}{\partial \theta}
$$

$$
Y_{n}^{m}(\theta)=\frac{m}{n} \frac{P_{n}^{m}(\theta)}{\sin \theta} .
$$

The intermediate coefficients, $a_{n}^{m}, b_{n}^{m}, c_{n}^{m}$ and $d_{n}^{m}$ are related to the quiet day SHA coefficients by:

$$
\begin{gathered}
a_{n}^{m e}=\frac{(n+1) a_{n}^{m}+c_{n}^{m}}{2 n+1} \\
a_{n}^{m i}=\frac{n a_{n}^{m}-c_{n}^{m}}{2 n+1} \\
b_{n}^{m e}=\frac{(n+1) b_{n}^{m}+d_{n}^{m}}{2 n+1} \\
b_{n}^{m i}=\frac{n b_{n}^{m}-d_{n}^{m}}{2 n+1} .
\end{gathered}
$$

Further details of computation of Legendre polynomials are given in Campbell (1997).

The external fields in orthogonal directions with $X$ pointing geomagnetic northward, $Y$ eastward and $Z$ into the Earth could be reconstructed from the external SHA coefficients as series of Fourier cosine and sine terms of the form:

$$
\begin{gathered}
X_{c}^{m}(\theta)=\sum_{n=m}^{12}\left(a_{n}^{m e}\right)\left(\frac{d P_{n}^{m}}{d \theta}\right) \\
X_{s}^{m}(\theta)=\sum_{n=m}^{12}\left(b_{n}^{m e}\right)\left(\frac{d P_{n}^{m}}{d \theta}\right) \\
Y_{c}^{m}(\theta)=-\left(\frac{m}{\sin \theta}\right) \sum_{n=m}^{12}\left(b_{n}^{m e}\right) P_{n}^{m} \\
Y_{s}^{m}(\theta)=\left(\frac{m}{\sin \theta}\right) \sum_{n=m}^{12}\left(a_{n}^{m e}\right) P_{n}^{m} \\
Z_{c}^{m}(\theta)=\sum_{n=m}^{12} n\left(a_{n}^{m e}\right) P_{n}^{m} \\
Z_{s}^{m}(\theta)=\sum_{n=m}^{12} n\left(b_{n}^{m e}\right) P_{n}^{m}
\end{gathered}
$$

$X_{c}^{m}, Y_{c}^{m}$ and $Z_{c}^{m}$ are the cosine coefficients of the external orthogonal field components, while $X_{s}^{m}, Y_{s}^{m}$ and $Z_{s}^{m}$ are the sine coefficients. The ' $e$ ' is replaced by ' $i$ ' in equation $(7 \mathrm{e}-\mathrm{h})$ when 
representing the internal horizontal components. For the vertical internal component, one should use

$$
\begin{aligned}
& Z_{c}^{m}(\theta)=-\sum_{n=m}^{12}(n+1)\left(a_{n}^{m i}\right) P_{n}^{m} \\
& Z_{s}^{m}(\theta)=-\sum_{n=m}^{12}(n+1)\left(b_{n}^{m i}\right) P_{n}^{m} .
\end{aligned}
$$

Hence, at any geomagnetic latitude $(90-\theta)$ or hour of the day $(\Phi / 15)$, the three orthogonal external or internal field components may be obtained from

$$
\begin{aligned}
& X(\theta, \Phi)=\sum_{m=1}^{4}\left[X_{c}^{m}(\theta) \cos m \Phi+X_{s}^{c}(\theta) \sin m \Phi\right] \\
& Y(\theta, \Phi)=\sum_{m=1}^{4}\left[Y_{c}^{m}(\theta) \cos m \Phi+Y_{s}^{c}(\theta) \sin m \Phi\right]
\end{aligned}
$$

$Z(\theta, \Phi)=\sum_{m=1}^{4}\left[Z_{c}^{m}(\theta) \cos m \Phi+Z_{s}^{c}(\theta) \sin m \Phi\right]$

using the separated external or internal coefficients or the sum of the two for the total Sq field.

Schuster $(1889,1908)$ used Gauss SHA method to prove that the daily quiet time geomagnetic field variations came mostly from sources of current external to the Earth. Using SHA method to separate the $\mathrm{Sq}$ ionospheric source currents from the induced currents within the Earth, the quiet fields were analyzed. Applying Schmucker (1970) transfer equations necessary for obtaining conductivity versus depth profile from the separated external and internal SHA as described in Campbell (1997), the depth (in $\mathrm{km}$ ) to a conductive layer was obtained from

$$
d_{n}^{m}=z-p .
$$

The conductivity $\sigma_{n}^{m}$ is given by:

$$
\sigma_{n}^{m}=\frac{5.4 \times 10^{4}}{m(\pi p)^{2}}(\text { Siemens } / \text { metre })
$$

where with

$$
a_{n}^{m e}+a_{n}^{m i}=A_{n}^{m}
$$

and

$$
b_{n}^{m e}+b_{n}^{m i}=B_{n}^{m}
$$

where $R$ is the Earth's radius, $a_{n}^{m e}$ and $b_{n}^{m e}$ are the external cosine and sine coefficients and $a_{n}^{m i}$ and $b_{n}^{m i}$ are the internal cosine and sine coefficients from the SHA of the Sq field.

For equations ( 8 and 9 ) to be valid for the analysis, it is required that

$$
0^{\circ} \geq \arg \left(C_{n}^{m}\right) \geq-45^{\circ}
$$

and

$$
80^{\circ} \geq \arg \left(S_{n}^{m}\right) \geq 10 \cdot 5^{\circ}
$$

where $S_{n}^{m}$ is the ratio of the internal to external components of the geomagnetic surface field and is given by

$$
S_{n}^{m}=u+i \nu
$$

and

$$
\begin{aligned}
& u=\frac{\left(a_{n}^{m e}\right)\left(a_{n}^{m i}\right)+\left(b_{n}^{m e}\right)\left(b_{n}^{m i}\right)}{\left(a_{n}^{m e}\right)^{2}+\left(b_{n}^{m e}\right)^{2}} \\
& \nu=\frac{\left(b_{n}^{m e}\right)\left(a_{n}^{m i}\right)-\left(a_{n}^{m e}\right)\left(b_{n}^{m i}\right)}{\left(a_{n}^{m e}\right)^{2}+\left(b_{n}^{m e}\right)^{2}}
\end{aligned}
$$

$C_{n}^{m}$ is Schmucker's complex transfer function (with real $z$ and imaginary $-p$ parts expressed by equations 10 and 11 respectively) which was modified by Campbell (1989) and is given by:

$$
C_{n}^{m}=z-i p
$$

It is also required that the SHA coefficient amplitudes must not be too small because the relative errors inherent in the SHA coefficients increase as the amplitudes of the coefficients decrease.

The analysis involved the selection of five magnetically quietest days from the internationally quietest days in each month. These five magnetically quietest days for each month are summed up hour by hour and the average computed. The Sq variations were determined followed by the Fourier

$$
z=\frac{R}{n(n+1)}\left\{\frac{A_{n}^{m}\left[n a_{n}^{m e}-(n+1) a_{n}^{m i}\right]+B_{n}^{m}\left[n b_{n}^{m e}-(n+1) b_{n}^{m i}\right]}{\left(A_{n}^{m}\right)^{2}+\left(B_{n}^{m}\right)^{2}}\right\}
$$

and

$$
p=\frac{R}{n(n+1)}\left\{\frac{A_{n}^{m}\left[n b_{n}^{m e}-(n+1) b_{n}^{m i}\right]-B_{n}^{m}\left[n a_{n}^{m e}-(n+1) a_{n}^{m i}\right]}{\left(A_{n}^{m}\right)^{2}+\left(B_{n}^{m}\right)^{2}}\right\}
$$


analyses of the two components of the magnetic field $(\mathrm{H}$, the horizontal and $\mathrm{Z}$, the vertical components). This was followed by the computation of Fourier analyzed values of $\mathrm{H}$ - and Z-components. Schmidt functions were then computed for the colatitude, followed by the determination of intermediate coefficients. Using the intermediate coefficients, the SHA coefficients were calculated to degree 12 and order 4 . The depths to conductive layers were then computed from equations $(8,10$ and 11). The associated conductivities were calculated from equation (9). The procedure for data analysis is summarized by the flow chart shown in figure 2 .

\section{Results}

The mantle electrical conductivity-depth structure of Niger delta in Nigeria is shown in figure 3. The scatter observed in the conductivity-depth values could be due to:

(i) error from field measurements,

(ii) error from the SHA fitting,

(iii) variability of source current location, and

(iv) magnetic field contributions produced by other than quiet time field conditions.
The small star is the conductivity-depth computation values while the solid line is the regression fitted values. The errors in profiling determination that arise from the noises in the original data and from the effects of lateral inhomogeneities are very difficult to evaluate accurately. What could be determined as error is only the measure of the profile regression fitting from the distribution of computed values. A detailed error analysis based on the standard deviation of the conductivity values from the profile regression fitting was carried out and the error bars on the conductivity-depth profile were plotted. The error bars on the conductivity-depth profile of figure 3 is shown in figure 4 . The error bars represent the standard deviations of the conductivity values from the profile regression fitting. The value of the standard deviation was found to be 0.016 .

The conductivity observed at a depth of about of $89 \mathrm{~km}$ was $0.032 \mathrm{~S} / \mathrm{m}$ which rose steadily to a value of $0.041 \mathrm{~S} / \mathrm{m}$ at $100 \mathrm{~km}$ and $0.09 \mathrm{~S} / \mathrm{m}$ at $221 \mathrm{~km}$. The conductivity profile continued increasing downward till it got to a value of $0.157 \mathrm{~S} / \mathrm{m}$ at a depth of $373 \mathrm{~km}$ (close to the base of upper mantle), $0.186 \mathrm{~S} / \mathrm{m}$ at $483 \mathrm{~km}$ and $0.201 \mathrm{~S} / \mathrm{m}$ at $784 \mathrm{~km}$. Finally it reached a value of $0.243 \mathrm{~S} / \mathrm{m}$ at a depth of $1179 \mathrm{~km}$ in the lower mantle. The steep increase in conductivity below $400 \mathrm{~km}$ indicates that in

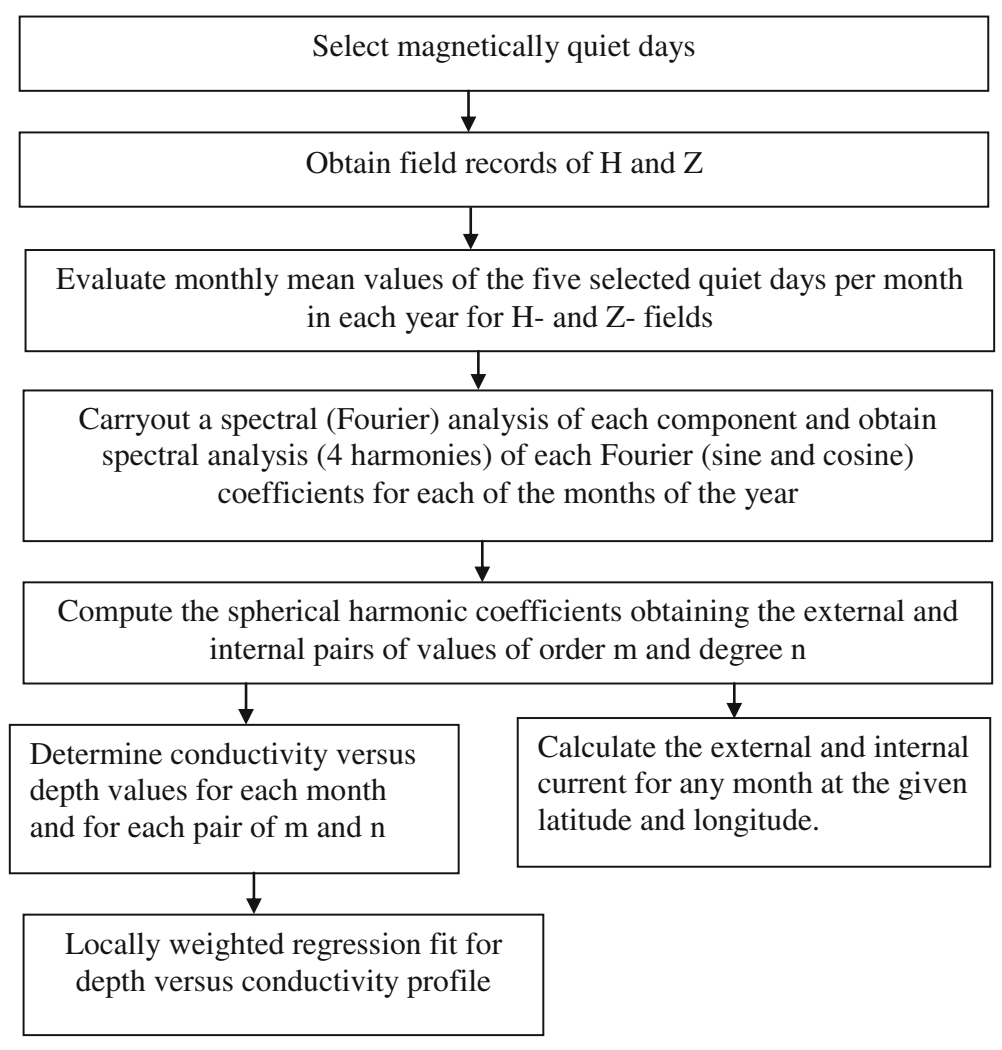

Figure 2. Data processing chart. 
West Africa and Asian regions, conductivity is very high below $400 \mathrm{~km}$ which agrees with Campbell and Schiffmacher's (1988) findings. There seemed to be some evidence of discontinuities near 100$290 \mathrm{~km}, 290-420 \mathrm{~km}, 420-630 \mathrm{~km}$ and $630-900 \mathrm{~km}$ and these locations are near phase change depths identified on seismic records by Dziewonski and Anderson (1981).

Our result compares favourably well with the results of similar works done by other researchers in different regions. Campbell and Schiffmacher (1988) worked in the South African region and found high conductivity values between about 150 and $350 \mathrm{~km}$ and a general increase thereafter which agrees with the result of this work. Arora et al. (1995) worked in the Himalayan region and

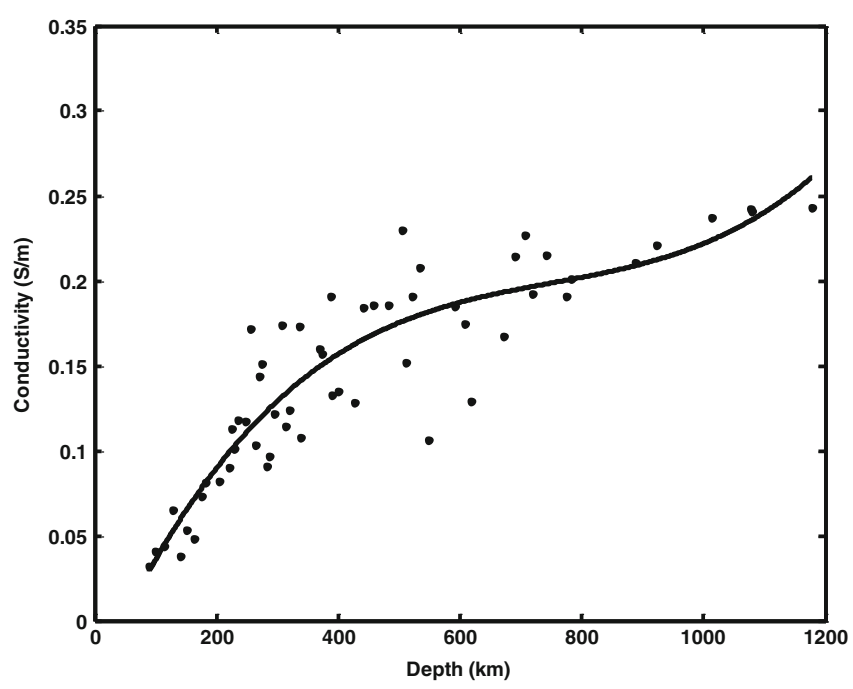

Figure 3. Mantle electrical conductivity-depth profile of Niger delta region.

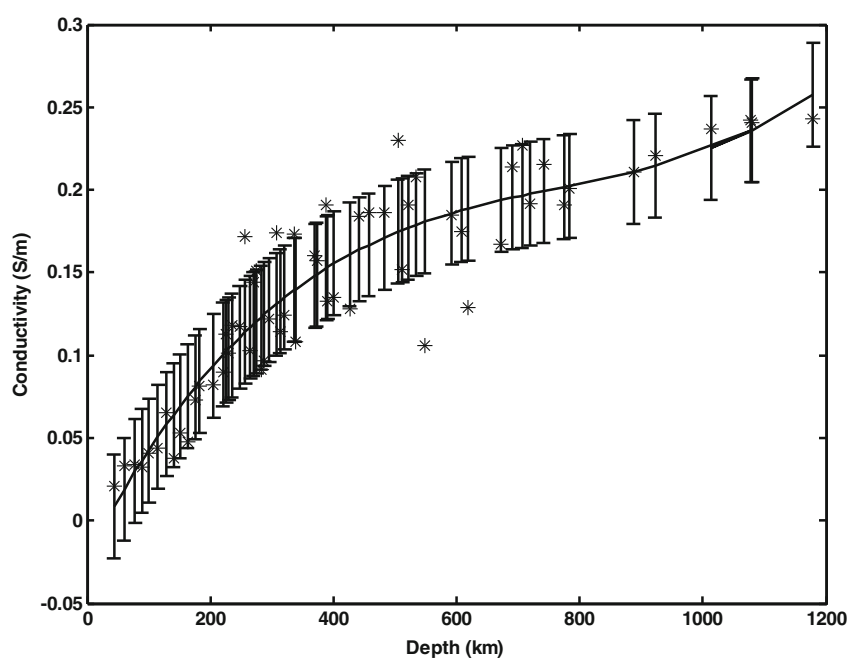

Figure 4. Error bar of mantle electrical conductivity-depth profile of Niger delta region. obtained conductivity values of $0.06 \mathrm{~S} / \mathrm{m}$ from $50 \mathrm{~km}$ to approximately $350 \mathrm{~km}$ depth with alternating relative maxima near 125 and $275 \mathrm{~km}$ interspersed by relative minima near 210 and $330 \mathrm{~km}$. The conductivity thereafter rises rapidly towards a value of $0.18 \mathrm{~S} / \mathrm{m}$ at $500 \mathrm{~km}$ depth with no sign of leveling off. In the work of Campbell et al. (1998) in the Australian region, the conductivity profile starts at $0.025 \mathrm{~S} / \mathrm{m}$ at a depth of $130 \mathrm{~km}$ and rises gradually to about $0.045 \mathrm{~S} / \mathrm{m}$ at $250 \mathrm{~km}$. The profile then steepens to $0.11 \mathrm{~S} / \mathrm{m}$ near $360 \mathrm{~km}$ and rises more gradually to about $0.13 \mathrm{~S} / \mathrm{m}$ at $470 \mathrm{~km}$. There were no further conductivity values until the region of near $800 \mathrm{~km}$ was reached showing about 0.18 $\mathrm{S} / \mathrm{m}$. Our conductivity profile is relatively higher than that of Campbell et al. (1998), which could be as result of lateral inhomogeneity. Obiekezie and Okeke (2010) worked in the West African subregion and got a conductivity profile which rose rapidly from $0.037 \mathrm{~S} / \mathrm{m}$ at a depth of $100 \mathrm{~km}$ to $0.09 \mathrm{~S} / \mathrm{m}$ at $205 \mathrm{~km}$. The profile then rose steadily till it reached $0.15 \mathrm{~S} / \mathrm{m}$ at $476 \mathrm{~km}$ near the base of the upper mantle, $0.2 \mathrm{~S} / \mathrm{m}$ at $880 \mathrm{~km}$ and $0.22 \mathrm{~S} / \mathrm{m}$ at $1200 \mathrm{~km}$ at the lower mantle. The conductivity profile of this work is in close agreement with that of Obiekezie and Okeke (2010). Figure 5 is a comparison of the conductivity-depth profile of this study with the conductivity-depth profiles of Obiekezie and Okeke (2010) and Campbell et al. (1998).

The results suggest that there may be detectable lateral differences in the electrical conductivity structure of the subcontinental mantle. The general correspondence observed in this work between high conductivity zone and low velocity zone, the asthenosphere, is in agreement with the global results of Tarits (1992). The main feature of

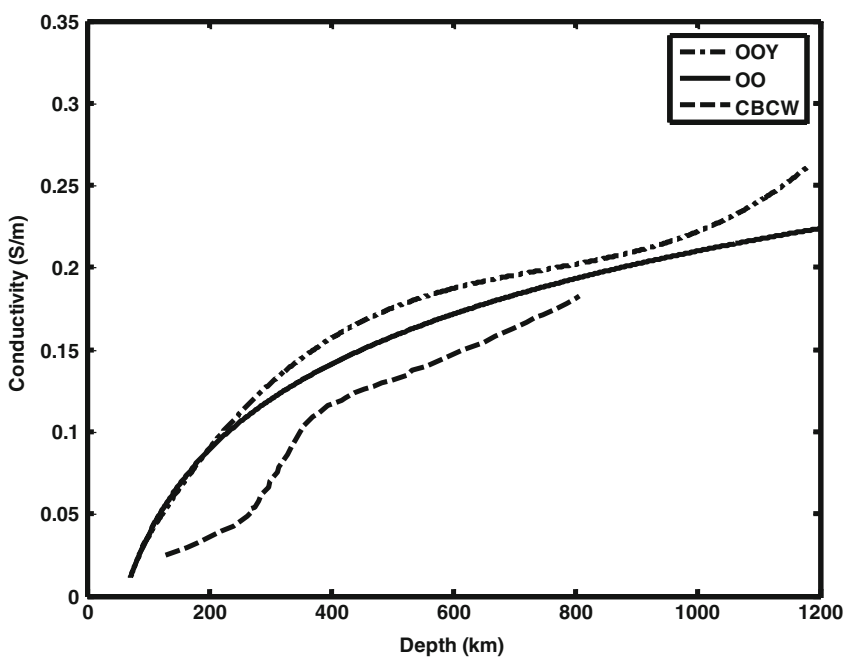

Figure 5. Comparison of the Niger delta region conductivity profile with other models. The result is labelled OOY (dashdotted line); OO: Obiekezie and Okeke 2010 (solid line); CBCW: Campbell et al. 1998 (dashed line). 
the conductivity-depth distribution in the mantle revealed by global studies is a downward increase of conductivity between depths of 300 and $1000 \mathrm{~km}$ (Bott 1982) which is evident in the result of this work.

The conductivity-depth profile of this study shows that the uppermost mantle in Niger delta in Nigeria could be seen as a stack of inhomogeneous layers in variance with the global model obtained under the assumption of a spherically symmetric earth (Banks 1972; Berdichevski et al. 1979) in which the upper mantle, down to 400$500 \mathrm{~km}$, depth is seen as a single homogeneous layer (Arora et al. 1995). The rapid increase in conductivity observed below $400 \mathrm{~km}$ depth is in conformity with the works of Campbell and Schiffmacher (1988) and Obiekezie and Okeke (2010) that the upper mantle under Africa and Asian regions is highly conductive.

The downward increase in conductivity agrees with the global models which depicted a steep rise in conductivity from 300-700 km (Campbell and Schiffmacher 1988; Arora et al. 1995; Campbell et al. 1998; Obiekezie and Okeke 2010).

Seismology has revealed some features of the upper mantle, such as the low velocity region between about 60 and $150 \mathrm{~km}$ depths and the large regional variations in primary $(\mathrm{P})$ and secondary (S) velocity structure. The most significant seismological feature of the upper mantle is the low velocity zone, which approximately coincides with the region of high seismic attenuation (low Q). Beneath the oceans and the continental tectonic regions, the low velocity zone may also coincide with a region of high electrical conductivity (Bott 1982). The most widely accepted explanation of the low velocity zone in oceanic and tectonic continental regions is that it contains a small melt fraction. The influence of a small melt fraction on seismic properties depends critically on whether the melt occupies isolated or interconnected cracks. O'Connell and Budiansky (1977) have shown that a liquid fraction of less than $1 \%$ occupying an interconnected network of cracks at grain boundaries could account for the observed reduction in seismic velocities and $Q$ value. Such an interpretation is supported by the high electrical conductivity zone underlying the oceanic lithosphere which appears to require the presence of a melt fraction occupying interconnected cracks.

\section{Conclusion}

This very first study of the mantle electrical conductivity structure in the Niger delta region using solar quiet day ionospheric current has yielded some interesting results which are entirely new for the area. Some of our results are in agreement with some existing results in other regions where similar studies had been done. Hence, we draw the following conclusions:

- The high conductivity zone observed from $100 \mathrm{~km}$ depth to about $219 \mathrm{~km}$ corresponds to the global seismic low velocity region (Dziewonski and Anderson 1981; Tarits 1992; Mechie et al. 1993; Arora et al. 1995; Campbell et al. 1998; Obiekezie and Okeke 2010).

- The downward increase in conductivity agrees with the global models which depicted a steep rise in conductivity from $300-700 \mathrm{~km}$ (Schultz and Larsen 1990; Arora et al. 1995).

- The sharp character of conductivity increase below 350-400 km depth, noted in this work supports the earlier inference of Campbell and Schiffmacher (1988) that, below $400 \mathrm{~km}$ depth, the upper mantle beneath central Asia and Africa is highly conductive.

- There seemed to be some evidence of discontinuities near 100-290 km, 290-420 km, 420-630 km and $630-900 \mathrm{~km}$ and these locations are near phase change depths identified on seismic records by Dziewonski and Anderson (1981) and Kennett and Engdahl (1991).

\section{Acknowledgements}

The authors are grateful to MAGDAS, Japan, for the data used in this work; Dan Okoh of Centre for Basic Space Science, University of Nigeria, Nsukka and Jonas Agbo of the Department of Physics and Astronomy, University of Nigeria, Nsukka, for their valuable contributions. They also thank immensely the reviewers for their thorough work and the Associate Editor (Dr Pawan Dewangan) for his meticulous and encouraging work.

\section{References}

Agha S O and Okeke F N 2007 Estimation of the conductivity-depth ratio of the various sub-regions of the upper mantle using Sq current; The Nigerian J. Space Res. 3 57-67.

Arora B R, Campbell W H and Schiffmacher E R 1995 Upper mantle electrical conductivity in the Himalayan region; J. Geomag. Geoelectr. 47 653-665.

Banks R J 1972 The overall conductivity distribution of the Earth; J. Geomag. Geoelectr. 24 337-351.

Berdichevski M N, Vanyan L L, Lagutinskaya L P, Rotanov N M and Fainber E B 1979 The experience of the Earth frequency sounding by the results of the spherical harmonic analysis of geomagnetic field variations; Geomag. Aeron. 10 374-377.

Bott M H P 1982 The interior structure of the Earth: Its structures constitution and evolution; Edward Arnold Ltd., London. 
Campbell W H 1997 Introduction to Geomagnetic Fields; Cambridge University Press, New York.

Campbell W H 1989 The regular geomagnetic field variations during quiet solar conditions; In: Geomagnetism (ed.) Jacobs J A (London: Academic Press) 3 385-460.

Campbell W H and Anderssen R S 1983 Conductivity of the subcontinental upper mantle: An analysis using quietday records of North America; J. Geomag. Geoelectr. 35 367-382.

Campbell W H and Schiffmacher E R 1988 Upper mantle electrical conductivity for seven subcontinental regions of the earth; J. Geomag. Geoelectr. 40 1387-1406.

Campbell W H, Barton C E, Chamalaun F H and Welsh W 1998 Quiet-day ionospheric currents and their application to upper mantle conductivity in Australia; Earth Planets Space 50 347-360.

Chapman S and Bartels J 1940 Geomagnetism; Oxford University Press.

Dziewonski A M and Anderson D L 1981 Preliminary reference Earth model; Phys. Earth Planet Inter. 25 297-356.

Gauss C F 1838 Allgemeine Theories des Erdmagnetismus in Resultate aus den Beobachtungen des magnetischen Vereins; In: Yahr (eds) Gauss C F and Weber W, translated from the German by E Sabine and R Taylor, Sci. Mem. Select. Trans. Foreign Acad. Learned Soc. Foreign J. 2 184-251.

Kennett B L N and Engdahl E R 1991 Travel times for global earthquake location and phase identification; Geophys. J. Int. 105 429-465.

Maxwell J C 1873 Treatise on Electricity and Magnetism; Cambridge University Press.
Mechie J A V, Egorkin K, Fuchs T, Ryberg L, Solodilov and Wenzel F 1993 P-wave mantle velocity structure beneath northern Eurasia from long-range recordings along the profile Quartz; Phys. Earth Planet. Inter. 79 269-286.

Obiekezie T N and Okeke F N 2010 Upper mantle electrical conductivity results from the dip equator latitudes of west African region; Int. J. Phys. Sci. 5(6) 637-641.

Obiora D N and Okeke F N 2011 Preliminary study of application of solar quiet daily (Sq) current variations in determining subsurface structure; The Nigerian J. Space Res. 10(1) $131-141$.

O'Connell R J and Budiansky B 1977 Viscoelastic properties of fluid-saturated cracked solids; J. Geophys. Res. 82 5719-5735.

Okeke F N 2000 Ionospheric quiet-day currents and their effects on the interpretation of upper mantle conductivity - A review; Surv. Geophys. 21 487-498.

Schmucker U 1970 An introduction to induction anomalies; J. Geomag. Geoelectr. 22 9-33.

Schultz A and Larsen J 1990 On the electrical conductivity of the midmantle: II. Delineation of heterogeneity by application of external inverse solutions; Geophys. J. Int. $101565-580$.

Schuster A 1889 The diurnal variation of terrestrial magnetism; Phil. Trans. Roy. Soc. A180 467-518.

Schuster A 1908 The diurnal variation of terrestrial magnetism; Phil. Trans. Roy. Soc. A208 163-204.

Tarits P 1992 Electromagnetic studies of global geodynamic processes; 11th Workshop on Electromagnetic Induction in the Earth, Victoria University of Wellington, 26 August-2 September, 1992, 7.1-7.21. 